\title{
Review of soft tissue coverage options in distraction osteogenesis of the extremity
}

\author{
Jacqueline Stoneburner', Beina Azadgoli', Anna C. Howell', Douglass Tucker², Geoffrey Marecek², \\ Joseph Carey ${ }^{1}$ \\ 'Plastic and Reconstructive Surgery, Keck School of Medicine of USC, Los Angeles, CA 90033, USA. \\ ${ }^{2}$ Orthopaedic Surgery, Keck School of Medicine of USC, Los Angeles, CA 90033, USA.
}

Correspondence to: Dr. Joseph Carey, Division of Plastic and Reconstructive Surgery in the Department of Surgery, Keck School of Medicine of USC, 1510 San Pablo St, Los Angeles, CA 90033, USA. E-mail: joseph.carey@med.usc.edu

\begin{abstract}
How to cite this article: Stoneburner J, Azadgoli B, Howell AC, Tucker D, Marecek G, Carey J. Review of soft tissue coverage options in distraction osteogenesis of the extremity. Plast Aesthet Res 2020;7:13. http://dx.doi.org/10.20517/2347-9264.2019.028
\end{abstract}

Received: 13 Sep 2019 First Decision: 15 Jan 2020 Revised: 12 Feb 2020 Accepted: 3 Mar 2020 Published: 20 Mar 2020

Science Editor: Matthew L. lorio Copy Editor: Jing-Wen Zhang Production Editor: Tian Zhang

\begin{abstract}
Aim: To review the choices of soft tissue coverage in distraction osteogenesis of the extremity.

Methods: A PubMed literature search yielded 14 articles included for systematic review. Data were extracted from each article if available (sample size, patient age, surgical indications, type of flap, use of additional modalities, method of bone osteogenesis, postoperative events, follow-up, satisfaction, weight-bearing status, and success rate). Unpaired $t$-tests were performed to compare complication rates. A retrospective review of three cases was also conducted.
\end{abstract}

Results: Fourteen articles discussed 145 patients with a mean age of 33.4 years and 146 extremity injuries followed over 3.3 years on average. Indications included chronic osteomyelitis or nonunion (58.2\%) and acute trauma (41.8\%). Average time from injury was 1.1 years. Ilizarov frame was used in 12 articles. Free flaps (88.0\%) or rotational flaps (12.0\%) were used, with muscle flaps (96.7\%) being most common. Most extremities received free latissimus dorsi or rectus abdominis flaps. Bone grafts and antibiotic beads were often used in conjunction. Although complications and reoperations were not uncommon (up to $30 \%$ ), $98.8 \%$ of patients on average were ultimately weight bearing and all articles reported $>91 \%$ success rate. Additionally, the rates of any complication were not statistically different between "fix and flap" protocol and flap or frame first. Lastly, a three-patient case series is presented.

Conclusion: Bone transport with soft tissue reconstruction remains an excellent choice for patients with large bony defects or who are unable to undergo autologous bone grafting. Not one surgical approach to limb salvage is superior, and decision should be made on a case by case basis between the surgeon and the patient.

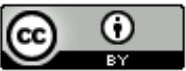

(C) The Author(s) 2020. Open Access This article is licensed under a Creative Commons Attribution 4.0 International License (https://creativecommons.org/licenses/by/4.0/), which permits unrestricted use, sharing, adaptation, distribution and reproduction in any medium or format, for any purpose, even commercially, as long as you give appropriate credit to the original author(s) and the source, provide a link to the Creative Commons license, and indicate if changes were made.

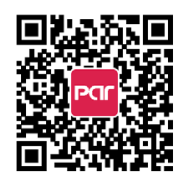


Keywords: Soft tissue coverage, free flaps, rotational flaps, microsurgery, bone osteogenesis, bone transport, lower extremity reconstruction, limb salvage

\section{INTRODUCTION}

High-energy lower extremity trauma with massive bone and soft tissue loss poses a challenge for orthopedic and reconstructive surgeons. Higher Gustilo-Anderson fracture type, Orthopaedic Trauma Association Open Fracture classification, and limb salvage index score are associated with a poor prognosis, including high risk of infection, nonunion, and amputation ${ }^{[1-3]}$. With improvements in surgical techniques and protocol-driven traumatic lower extremity management at tertiary care centers, limb salvage rates have significantly increased, reaching up to $90 \%$ in some reports ${ }^{[4-6]}$.

Early aggressive radical debridement, skeletal stabilization and soft tissue coverage is the critical first step in lower extremity salvage ${ }^{[7]}$. Depending on the extent of trauma and the size and nature of the defect, there are many reconstructive options available to the orthopedic and plastic surgeon. When the bony injury is "critical sized" - that is, too large to heal without additional intervention - additional steps must be taken to achieve bony union.

The choice of reconstructive technique is often determined by size. The induced membrane technique is a viable option for small and large defects, although results may differ based on anatomic location. Larger defects may require vascularized transfer from the fibula or iliac crest ${ }^{[7-9]}$. Some patients may be poor candidates for vascularized bone graft, the defect may exceed the size of the available graft or there may be concerns about size mismatch between vascularized bone and the defect location. In these cases, bone transport using distraction osteogenesis can be utilized. Bone transport in combination with free soft tissue transfer is an effective treatment for nonunions, segmental defects, and osteomyelitis.

This systematic review summarizes and discusses reconstructive options available for traumatic extremity injuries when bony transport and free tissue transfer are required for limb salvage. A series of case examples in combination with the senior authors' surgical techniques at a single academic institution is described.

\section{Bone deficit treatment options}

Critical bone loss is devastating for patients; orthopedic and plastic surgeons must be prepared to treat these patients with a multidisciplinary approach. It most commonly occurs in patients following trauma, infection, and oncologic resection. Critical bony defects, by definition, necessitate additional intervention, as the defect is too large to undergo the normal physiologic healing process. The inability for bone to spontaneously regenerate is often largely controlled by the presence or absence of periosteal blood supply, as well as a viable docking site for reduction ${ }^{[10]}$. Defects greater than $2.5 \mathrm{~cm}$ are usually considered critical, although there is poor evidence and thus some disagreement between experts with this definition ${ }^{[11-13]}$. In these situations, primary bone grafting is also insufficient to obtain union. More advanced treatment options include the induced membrane technique and bone transport through distraction osteogenesis.

\section{Induced membrane techniques}

The induced membrane technique, often eponymously referred to as the Masquelet technique, is a twostage technique involving placement of a foreign body within the defect that results in a biologicallyactive membrane around the defect, which can then provide biology for subsequent bone formation using graft $^{[14,15]}$. The first stage entails radical debridement and skeletal stabilization ${ }^{[15,16]}$. A spacer, typically made from polymethylmethacrylate cement, is placed. A pseudomembrane will form around the spacer. This spacer is biologically active and contains growth factors involved in fracture healing and angiogenesis. In 
the second stage, the previous incision is reopened, the pseudomembrane is incised, bone graft is placed into the defect, and the membrane is closed around the graft.

\section{Autologous bone grafting}

The graft used in this technique is typically autogenous bone graft. Autologous graft is histocompatible, osteoconductive, osteoinductive, and osteogenic ${ }^{[17,18]}$. This provides a structure through which bone, host capillaries, and mesenchymal stem cells can have in-growth. The source of autogenous bone is determined by many factors including location of bone defect, desired function of bone graft, size of bone defect, associated complications, and expected graft site. Locations and methods for graft include the distal tibia, calcaneus, proximal tibia, iliac crest, and via the Reamer-Irrigator-Aspirator system. The optimal timing for placement for the bone graft is debated, with studies suggesting peak osteo- and angiogenic properties occur at 4 weeks, with a subsequent decline ${ }^{[19-21]}$. In situations in which the induced membrane technique is contraindicated, the orthopedic surgeon's best option for attaining bony union is by means of bone transport.

\section{Distraction osteogenesis}

Indications for bone transport via distraction osteogenesis include massive bone loss (greater than $5 \mathrm{~cm}$ ), inadequate soft-tissue coverage, infection, and the need for prolonged stability. However, even with defects this large, other methods along with bone transport should be considered. Of paramount importance, the surgeon must be competent in managing such patients throughout the entirety of their care, as it has been suggested that the success of bone transport is highly dependent upon surgeon experience ${ }^{[22]}$.

Distraction osteogenesis (DO) was described by Ilizarov. The classic method utilizes thin-wire circular frames to provide stability and gradually distract at the osteotomy site. This method of DO was developed in the 1950 s and has been a popular method for long bone expansion in Europe and the United States since the 1980 s as a treatment modality for critical bone loss. All distraction osteogenesis is dependent on three things: a low-energy corticotomy, bony stability, and distraction with a specific rate and rhythm ${ }^{[23,24]}$. After the bone defect is defined, circular external fixation with thin K-wires are percutaneously fixated to healthy bone both proximal and distal to the site of bone loss. They are held under tension via fixation bolts to the rings surrounding the affected limb fragments. These rings are then joined using threaded rods or adjustors. The use of multiple fixation rings for each segment allows for increased control of the bone segments, allowing for an increased number of connecting rods and greater ability for bone gap repair ${ }^{[2]}$. Each case will progress through three phases: latency, in which the healing process begins; distraction, during which time the DO focus is distracted at a specific rate and rhythm; and consolidation, in which the regenerate ossifies ${ }^{[25]}$.

Ilizarov's method of DO can reliably achieve bony union in limbs that would otherwise not be salvageable. Time of distraction is variable and dependent on defect size, location, and host factors. The maximum rate of distraction is $1 \mathrm{~mm} /$ day, and consolidation typically requires twice as long as the distraction phase ${ }^{[26-29]}$ The published rates of successful limb reconstruction approach $100 \%$ in most publications ${ }^{[30-34]}$. Complication of DO include pin-site infections, stretching of neurovascular structures, soft-tissue scarring, poor regenerate, and non-union of the docking site ${ }^{[30,35]}$. Classic Ilizarov DO is still widely utilized, but alternative techniques such as cable transport and all-internal techniques using motorized medullary nails have proven successful. These techniques offer similar outcomes with decreased time with external fixation, allowing for improved patient comfort, decreased site infection risk, and sooner time to rehabilitation.

One potential alternative to classical Ilizarov DO is utilization of Taylor Spatial Frames. This unique frame has dual rungs with six struts allowing for telescoping ${ }^{[36,37]}$, thus providing many of the same benefits to Ilizarov DO but with the ability to provide correction in six planes (coronal angulation/translation, sagittal 
angulation/translation, rotation, and shortening). In addition, this system has the ability to utilize computer accuracy $^{[36-38]}$. Studies have shown this to be as effective as, but not superior to, classical Ilizarov DO in overall clinical outcomes ${ }^{[38-41]}$, while some advantages include use for residual deformity following Ilizarov DO, lower rate of return to the OR, and the ability to correct in all planes ${ }^{[36]}$.

Finally, the pull wire system is a newer technique that can induce bone transport with utilizing both internal and external fixation through medullary nail placement ${ }^{[42]}$. This dual distraction method provides similar rates of healing to classical Ilizarov DO, while limiting the risks associated with long-term external fixator use ${ }^{[42,43]}$. Rozbruch et al ${ }^{[33]}$ (2008) also suggested that there is expedited bone healing and a decreased risk of refracture of the site of bone transport.

\section{Soft tissue coverage in lower extremity trauma}

In many cases of lower extremity trauma, free tissue transfer becomes necessary in an attempt at limb salvage. While successful flap reconstruction may be achieved, complication rates are relatively high in lower extremity reconstruction for a variety of reasons, which may include trauma-induced edema, preexisting vascular conditions, other patient comorbidities, or poor patient compliance during postoperative recovery.

In a meta-analysis conducted by Xiong and colleagues on free flap reconstruction of lower extremity defects, total flap loss and the rate of thrombosis were both found to be about $6 \%{ }^{[4]]}$. Overall, $26.1 \%$ of the flap losses were due to venous thrombosis, whereas $10.1 \%$ were due to arterial thrombosis. Minor complications such as hematoma, partial necrosis, infection, and wound dehiscence occurred at rates between $4.0 \%$ and $8.0 \%{ }^{[44]}$.

Given the heterogeneity of lower extremity trauma, several different reconstructive options can be utilized by the plastic surgeon, depending on the size of the defect, the structures involved, and the comfort level of the surgeon.

Historically, muscle flaps were believed to reduce infection rates in contaminated wounds. However, more recently, free fasciocutaneous flaps have proven to be comparable to muscle flaps in terms of success rates, infection rates, and bony union in lower extremity reconstruction ${ }^{[4,45-47]}$. Additionally, fasciocutaneous flaps are thought to be simpler to re-elevate for subsequent orthopedic procedures, require fewer secondary skin graft procedures, and result in lower donor site morbidity ${ }^{[46-49]}$.

In a meta-analysis conducted by Bekara et al. ${ }^{[50]}$, the most commonly used free flaps for distal third lowerlimb reconstruction were found to be the latissimus dorsi muscle flap (25.5\%), anterolateral thigh flap (19.7\%), rectus abdominis muscle flap (8.5\%), gracilis muscle flap $(8.4 \%)$, and serratus anterior flap $(6.4 \%)^{[50]}$. The majority of flaps used $(56.5 \%)$ were muscular flaps, followed by fasciocutaneous $(42 \%)$ and fascial $(0.5 \%)$. The most common pedicled-propeller flaps were reportedly posterior tibial artery perforator (5.86\%), peroneal artery perforator (30.1\%), sural artery perforator (5.6\%), metatarsal artery perforator $(2.0 \%)$, anterior tibial artery perforator $(1.6 \%)$, lateral retromalleolar artery perforator $(1.6 \%)$, and dorsalis pedis artery perforator $(0.3 \%)^{[50]}$.

Regarding free versus pedicled flaps in reconstruction of the distal third of the lower limb, the same review by Bekara et al ${ }^{[50]}$ concluded that, while partial flap necrosis is higher in pedicled-propeller flaps, wound dehiscence and infection rates are higher in free flaps. Failure and overall complication rates were similar in both groups ${ }^{[50]}$.

In addition to the flap that is used, the reconstructive surgeon must also select the appropriate recipient vessel and anastomotic technique. While studies have shown no difference in complication rates between 
end-to-end and end-to-side arterial anastomoses, end-to-side anastomoses are generally the preferred choice for extremities at risk for vascular insufficiency in order to maintain perfusion to the distal leg and foot ${ }^{[51,52]}$.

While it was previously thought that only vessels proximal to the injury could be used as recipient vessels for free flap coverage, it has since been shown that there is no difference in outcomes or reoperation rates when flaps are anastomosed to vessels distal to the injury ${ }^{[53,54]}$.

\section{Bone transport with simultaneous soft tissue reconstruction}

It is now well-established that early soft tissue coverage of complex lower extremity trauma leads to successful limb salvage with improved flap success rates and lower rates of infection ${ }^{[55-58]}$. Thus, the current practice at most institutions is simultaneous bony fixation and soft tissue coverage. This so-called "fix and flap" protocol, consisting of radical debridement and skeletal stabilization with immediate or very early free flap coverage, has resulted in faster union times with lower infection rates ${ }^{[59,60]}$.

To overcome segmental bone loss and manage later consequences of lower extremity trauma such as malunion or nonunion, bone transport is often used. By combining free tissue transfer with bone transport, large segmental and soft tissue defects can be simultaneously treated with great success. Flap coverage combined with bone transport allows for better limb length restoration by maintaining length from the start; improving vascularity, which is important for fracture healing; and facilitating bone grafting or other subsequent procedures at the docking site ${ }^{[6]]}$.

While classically, the injured limb with critical bony defect was initially treated by debridement and resection and shortening of bone to allow for primary soft tissue closure, the more recent practice of combining free tissue transfer with bone transport allows for maintenance of the limb's original length and avoids the frequent complications associated with the traditional compression-distraction technique. The free flap provides healthy vascularized soft tissue, under which distraction osteogenesis can then take place $^{[7]}$.

Few studies have described the effects of distraction on the transferred free tissue and its anastomotic pedicle. Jupiter et al. ${ }^{[62]}$ reported that both the free tissue and the native tissue show equal magnitude of stretch and lengthening without any scar dehiscence after bone transport despite their different tensile strength and mechanical properties. Many studies have shown that, with major vessel repair in lower extremity trauma, the anastomotic site tolerates initial distraction process as early as 2-3 days after surgery ${ }^{[62-64]}$. However, the outcome of the microvascular anastomosis in these cases has not yet been reported. It has been demonstrated, however, that immediate distraction osteogenesis with a recent free flap has not been found to compromise the flap ${ }^{[61]}$.

Finally, while placement of pins through the free flap has also been noted to be safe, caution must be taken when placing the pins so that their anticipated path does not pierce the pedicle ${ }^{[62,65]}$. Careful planning and collaboration between the orthopedic surgeon and reconstructive surgeon are needed for these cases to ensure safe distraction against the pedicle and microvascular anastomosis.

Another potential option for patients needing both soft tissue coverage and assistance with bony growth is a medial femoral condyle vascularized graft. First described in the 1990s, this method utilizes the highly vascularized periosteum and either the medial superior genicular or more commonly the descending genicular artery, due to its length and ease of identification ${ }^{[6-68]}$. This method usually follows failure of conventional therapies and has been proven to be efficacious for osteomyelitis, avascular necrosis (AVN), and nonunions. Specifically, it has been used for the humerus and ulna ${ }^{[69-72]}$, as well as tibial and femoral 
defects ${ }^{[0,73,74]}$. Notably, this methodology has been well studied in the treatment of scaphoid $\mathrm{AVN}^{[6,68,75]}$, with studies reporting up to $100 \%$ of patients achieving union ${ }^{[76,77]}$ and level III evidence that it is superior to 1,2 -intercompartmental supraretinacular artery graft ${ }^{[6,77,78]}$. Finally, these studies have reported limited to no complications at both donor and recipient $\operatorname{sites}^{[73,77,79,80]}$.

\section{METHODS}

\section{Literature review}

A systematic review of the literature was performed using PubMed database in adherence with PRISMA guidelines. Combinations of the following search terms were used: "bone transport' AND 'free tissue transfer", "Ilizarov' AND 'free tissue transfer", and "'distraction osteogenesis' AND 'soft tissue coverage". No limits were placed on any of the search queries. All articles were independently reviewed by two authors. Following the primary search, titles and abstracts were either included or excluded based on predefined eligibility criteria. Inclusion criteria included bone transport as research theme, involvement of soft tissue coverage, relevance to limb salvage, and general population as the sample. Articles were limited to English language and review articles, letters, and comments. Subsequently, evaluation of the full text of selected articles was similarly performed and their bibliographies were assessed for additional articles to include.

Articles that described patient outcomes, details of bone transport, and type of soft tissue coverage were included. Studies were excluded if they had inadequate data, did not involve a combination of bone transport and soft tissue coverage, or were anecdotal in nature.

The following data from each article were extracted: sample size, mean patient age, indications for intervention, type of flap, use of additional modalities (antibiotic beads or bone substitute, vein or bone graft, and hardware), details of bone osteogenesis (average bone and soft tissue defect, time-to and rate of distraction, and total distraction), postoperative events (complications, total or partial flap loss, skin graft complication, hematoma, nonunion, malunion, infection, recurrent osteomyelitis, broken fixation wires, flap depression, bone exposure, fracture, limb-length discrepancy, second flap surgery or reoperation, and amputation), average follow-up, satisfaction, weight bearing status, and success rate.

Unpaired $t$-tests were utilized to assess if complication rates were statistically significant between the simultaneous placement of frame and flap and the placement of the flap before or after fixation. Fisher's exact test was used to compare differences in complication rates in patients with acute and chronic wounds. Statistical significance was determined at $P<0.05$.

\section{Case series}

A retrospective review was conducted of patients undergoing bone transport with simultaneous soft tissue coverage performed at the Keck Hospital of the University of Southern California between 2016 and 2019. Three non-consecutive cases performed by a single plastic and orthopedic surgeon are described below.

\section{RESULTS}

Our initial literature search identified 91 unique articles, of which 13 full text-articles were assessed for inclusion. Six full-text articles from the search were ultimately included, added to eight articles selected from additional search. These 14 articles ${ }^{[7,9,61,65,81-90]}$ were utilized for analysis [Figure 1].

The selected articles included bone transport with soft tissue reconstruction in 145 patients with a mean age of 33.4 years and a total of 146 extremity injuries (142 lower extremity and 4 upper extremity injuries). Ten of the 14 articles included average duration of follow up [Table 1$]^{[7,9,61,65,81-90]}$. Patients were followed over 3.3 years 


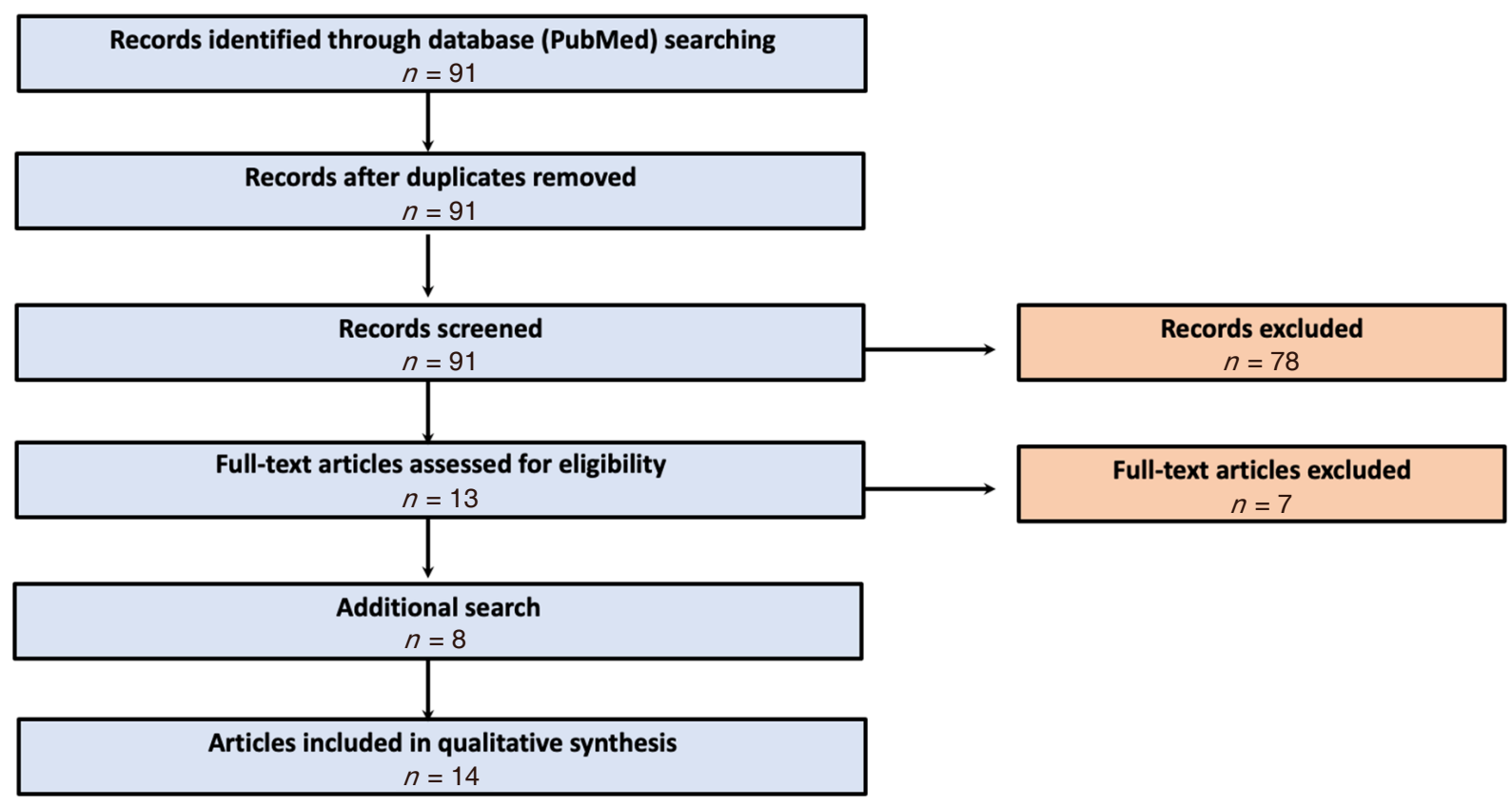

Figure 1. Flow diagram of the literature search

Table 1. Studies included in systematic review

\begin{tabular}{|c|c|c|c|c|c|c|c|}
\hline Ref. & $\begin{array}{c}\text { No. of } \\
\text { patients }\end{array}$ & $\begin{array}{l}\text { Mean age } \\
\text { (years) }\end{array}$ & $\begin{array}{l}\text { No. of lower } \\
\text { extremities }\end{array}$ & $\begin{array}{l}\text { No. of upper } \\
\text { extremities }\end{array}$ & $\begin{array}{l}\text { Average time of repair } \\
\text { from injury (months) }\end{array}$ & Frame & $\begin{array}{l}\text { Avg follow } \\
\text { up (years) }\end{array}$ \\
\hline Lowenberg et al. $^{[81]}$ & 34 & 40 & 34 & 0 & NR & Ilizarov frame & 11 \\
\hline Musharafieh et al. ${ }^{[82]}$ & 3 & NR & 3 & 0 & 0.71 & Anterior double-stacking & 1.5 \\
\hline Bibbo $^{[83]}$ & 1 & 37 & 1 & 0 & 24 & Ilizarov frame & 2 \\
\hline Duman et al. ${ }^{[84]}$ & 9 & 22 & 9 & 0 & NR & Ilizarov frame & NR \\
\hline Fiebel et $a l^{[65]}$ & 1 & 41 & 1 & 0 & 24 & Ilizarov frame & 3 \\
\hline \multicolumn{8}{|l|}{ Lowenberg et al. ${ }^{[61]}$} \\
\hline Simultaneous group & 13 & 31 & 12 & 1 & NR & Ilizarov frame & 2 \\
\hline Delayed group & 23 & 44 & 20 & 3 & NR & Ilizarov frame & 2 \\
\hline Spiro et al. ${ }^{[9]}$ & 5 & 42 & 5 & 0 & NR & $\begin{array}{l}\text { Modified Ilizarov in } 3 \text { pts, } \\
\text { Ilizarov frame in } 2 \text { pts }\end{array}$ & NR \\
\hline Tukiainen and Asko-Seljavaara ${ }^{[7]}$ & 4 & 31 & 4 & 0 & NR & Ilizarov frame & NR \\
\hline Minehara et al. ${ }^{[85]}$ & 1 & 18 & 1 & 0 & 0.6 & Ilizarov or hybrid frame & NR \\
\hline Boopalan and Jepegnanam ${ }^{[86]}$ & 2 & 27.5 & 2 & 0 & 7.5 & Ilizarov frame & 1 \\
\hline Lowenberg and Van der Reis ${ }^{[87]}$ & 1 & 23 & 1 & 0 & 12 & Ilizarov frame & 1.25 \\
\hline Hutson et al. ${ }^{[88]}$ & 18 & 32 & 19 & 0 & 1.13 & Ilizarov frame & 4.83 \\
\hline Chim et al. ${ }^{[89]}$ & 28 & 45 & 28 & 0 & 36.1 & Taylor spatial frame & 4.1 \\
\hline Isik et al. ${ }^{[90]}$ & 2 & NR & 2 & 0 & NR & Ilizarov frame & NR \\
\hline
\end{tabular}

NR: not reported

on average (range of 1-11 years). Indications for surgery included chronic osteomyelitis or nonunion (58.2\% of patients) and acute trauma with or without infection (41.8\% of patients) [Table 2]. No studies included patients with tumors or masses. The average time from injury was 1.1 years (range of 18 days to 3 years) in 8 of the 14 articles. An additional 2 of the 14 articles reported two separate times from injury: $1^{[7]}$ or $3^{[81]}$ weeks for patients with acute trauma and $10^{[81]}$ or $18^{[7]}$ months for patients with chronic osteomyelitis or nonunion.

All 14 articles described a surgical approach. In 11 of the 14 articles, the authors used a classic Ilizarov frame; in one, they used either an Ilizarov frame or segmental transport external fixator; and, in one, they used a hexapod frame. Only 1 of the 14 used anterior double-stacking external fixation. Some patients 
Table 2. Indications for surgery

\begin{tabular}{lccc}
\hline Indications for surgery & No. of articles & No. of extremities & Percentage of extremities (\%) \\
\hline Osteomyelitis & 9 & 85 & 58.2 \\
Nonunion & 3 & 61 & 41.8 \\
Acute trauma (+/-infection) & 9 & 146 & \\
Total articles & 14 & & \\
\hline
\end{tabular}

Table 3. Surgical approach

\begin{tabular}{lccc}
\hline Surgical approach & No. of articles & No. of extremities & Percentage of extremities (\%) \\
\hline Flap first & 9 & 83 & 56.8 \\
Simultaneous application of flap and frame & 7 & 54 & 37.0 \\
Frame first & 4 & 9 & 6.2 \\
Total articles & 14 & 146 & \\
\hline
\end{tabular}

Table 4. Type of flap

\begin{tabular}{lccc}
\hline Type of flap & No. of articles & No. of extremities & Percentage of extremities (\%) \\
\hline Rectus abdominis & 9 & 47 & 40.9 \\
Free latissimus dorsi & 12 & 11 & 36.5 \\
Rotational gastrocnemius & 4 & 3 & 9.6 \\
Reverse sural & 2 & 3 & 2.6 \\
Soleus & 1 & 2 & 1.7 \\
Radial forearm flow-through & 2 & 2 & 1.7 \\
Rotational latissimus dorsi* & 2 & 2 & 1.7 \\
Cross leg & 2 & 1 & 0.9 \\
Serratus & 1 & 1 & 0.9 \\
Gracilis & 1 & 1 & 0.9 \\
Combined LD + serratus & 1 & 115 & \\
Total articles & 13 & & \\
\hline
\end{tabular}

*Used for upper extremity reconstruction. LD: latissimus dorsi

underwent simultaneous application of frame and soft tissue flap (37.0\%) while others had the application of a flap first (56.8\%) or frame first (6.2\%) [Table 3]. With respect to soft tissue reconstruction, four of the 14 articles quantified the soft tissue defect. The average soft tissue defect was $125 \mathrm{~cm}^{2}$ (range of $88-219 \mathrm{~cm}^{2}$ ).

All 14 articles discussed the general type(s) of flaps used. Soft tissue reconstruction was most commonly performed with free flaps $(88.0 \%)$ as opposed to rotational flaps $(12.0 \%)$. Of these, most were muscle flaps (96.7\%) with fewer being fasciocutaneous flaps (3.3\%). However, only 13 of the 14 articles specified the type of flap used for each procedure. The most frequently used flaps were free latissimus dorsi and rectus abdominis, followed by rotational gastrocnemius [Table 4]. Seven of the 14 articles discussed type of anastomosis. End-to-side anastomosis $(55.2 \%)$ was performed slightly more often than end-to-end anastomosis (44.8\%), and, while a large range of recipient vessels was used, posterior tibial (53.2\%) and anterior tibial (24.2\%) were the most common [Table 5].

With regard to bone reconstruction and transport, bone defect was mentioned in nine articles, whereas total length of distraction was mentioned in four of the 14 articles. The average bone defect was $8.9 \mathrm{~cm}$ (range of $6.0-12.5 \mathrm{~cm}$ ) and average total distraction was $6.1 \mathrm{~cm}$ (range of 4.3-10 cm). The time to distraction was discussed in five of the 14 articles, and rate of distraction was discussed in six of the 14 articles. The average time to distraction was 24.1 days (range of 7-73.5 days) and the average rate of distraction was $0.96 \mathrm{~mm} /$ day (range of $0.75-1 \mathrm{~mm} /$ day).

As discussed in 11 of the 14 articles, additional techniques were utilized for some extremities. These techniques included bone graft (62.3\%), antibiotic beads (48.6\%), antibiotic bone substitute (13.0\%), vein 
Table 5. Recipient vessels

\begin{tabular}{lccc}
\hline Recipient vessels & No. of articles & No. of extremities & Percentage of extremities (\%) \\
\hline Posterior tibial & 6 & 33 & 53.2 \\
Anterior tibial & 5 & 15 & 24.2 \\
Peroneal & 3 & 5 & 8.1 \\
Sural & 1 & 5 & 8.1 \\
Popliteal & 3 & 3 & 4.8 \\
Femoral a./v. with saphenous graft & 1 & 1 & 1.6 \\
Total articles & 7 & 62 & \\
\hline
\end{tabular}

a.: artery; v.: vein

Table 6. Complications in extremities based on timing of flap vs, frame placement

\begin{tabular}{lccc}
\hline & Simultaneous flap and frame & Flap before or after frame & $\boldsymbol{P}$-value \\
\hline Amputations & $0 / 50$ & $2 / 82$ & 0.45 \\
Flap failure & $1 / 50$ & $6 / 82$ & 0.32 \\
\hline
\end{tabular}

$P<0.05$ used for statistical significance

graft $(2.7 \%)$, and hardware (0.7\%). Eleven of the 14 articles documented complications in 141 patients, including nonunion $(n=11,7.8 \%)$, malunion $(n=10,7.1 \%)$, flap depression or irregularity $(n=10,7.1 \%)$, total flap loss $(n=9,4.9 \%)$, partial flap loss $(n=6,4.3 \%)$, infection requiring readmission or i.v. antibiotics $(n=8,5.7 \%)$, significant limb-length discrepancy $(n=8,5.7 \%)$, bone exposure $(n=4,2.8 \%)$, fracture $(n=2$, $1.4 \%)$, hematoma $(n=2,1.4 \%)$, skin graft complication $(n=1,0.8 \%)$, and broken fixation wires $(n=1,0.8 \%)$. Ten of the 14 articles also discussed 140 extremities requiring reoperation $(n=42,30 \%)$, by far mostly for docking procedures, second flap surgery $(n=9,6.4 \%)$, or amputations $(n=2,1.4 \%)$.

Complications were further assessed based on timing of soft tissue coverage, which occurred simultaneously with bone transport frame as well as before or after bone transport. Starting with simultaneous placement of flap and frame, five of the 14 articles used this approach for 50 patients with a mean age of 34.4 years in 50 extremities [Table 6 and Figure 2]. Three extremities needed reoperation; however, none required amputation or a second flap surgery. These articles reported infections requiring readmission or i.v. antibiotics $(n=5,10 \%)$, nonunions $(n=4,8.0 \%)$, malunions $(n=3,5.8 \%)$, partial flap loss ( $n=1,2 \%)$, total flap loss $(n=1,2 \%)$, fracture $(n=1,2 \%)$, and limb-length discrepancy $(n=1,2 \%)$ in several extremities. In contrast, seven of the 14 articles documented complications after soft tissue reconstruction with flaps either before or after application of frame used for bone transport [Table 5 and Figure 2]. This method included 82 extremities of 81 patients with a mean age of 32.9 years. A higher number of extremities required amputations $(n=2,2.4 \%)$, reoperation $(n=25,30.5 \%)$, and second flap surgery $(n=7,8.5 \%)$. Similar to the simultaneous group, these articles reported total flap losses $(n=6,7.3 \%)$, partial flap losses $(n=5,6.3 \%)$, nonunions $(n=7,8.5 \%)$, malunions $(n=6,7.3 \%)$, limb-length discrepancies $(n=7,8.5 \%)$, infections requiring readmission or i.v. antibiotics $(n=3,3.7 \%)$, and fracture $(n=1,1.2 \%)$ in a number of extremities. Additionally, this group reported flap irregularities or depression $(n=8,9.7 \%)$, bone exposures $(n=2$, $2.4 \%)$, skin graft complication $(n=1,1.2 \%)$, hematoma $(n=1,1.2 \%)$, and broken fixation wires $(n=1$, $1.2 \%$ ). Of note, there was no statistical significance between the rates of any complication between the 2 groups.

Total flap loss, or flap failure, was identified in four different articles, one of which also reported amputation as subsequent management. Of the four articles, only one ${ }^{[81]}$ employed the simultaneous "fix and flap" technique, in which one flap failed out of the 34 reconstructions performed (2.9\%). However, this patient's condition, flap choice, and postoperative management are not included. The remainder of the studies ${ }^{[82,88,89]}$ utilized flap surgery before or after fixation. Musharafieh et al. ${ }^{[82]}$ described 3 case reports, 


\section{Percent of Extremities}

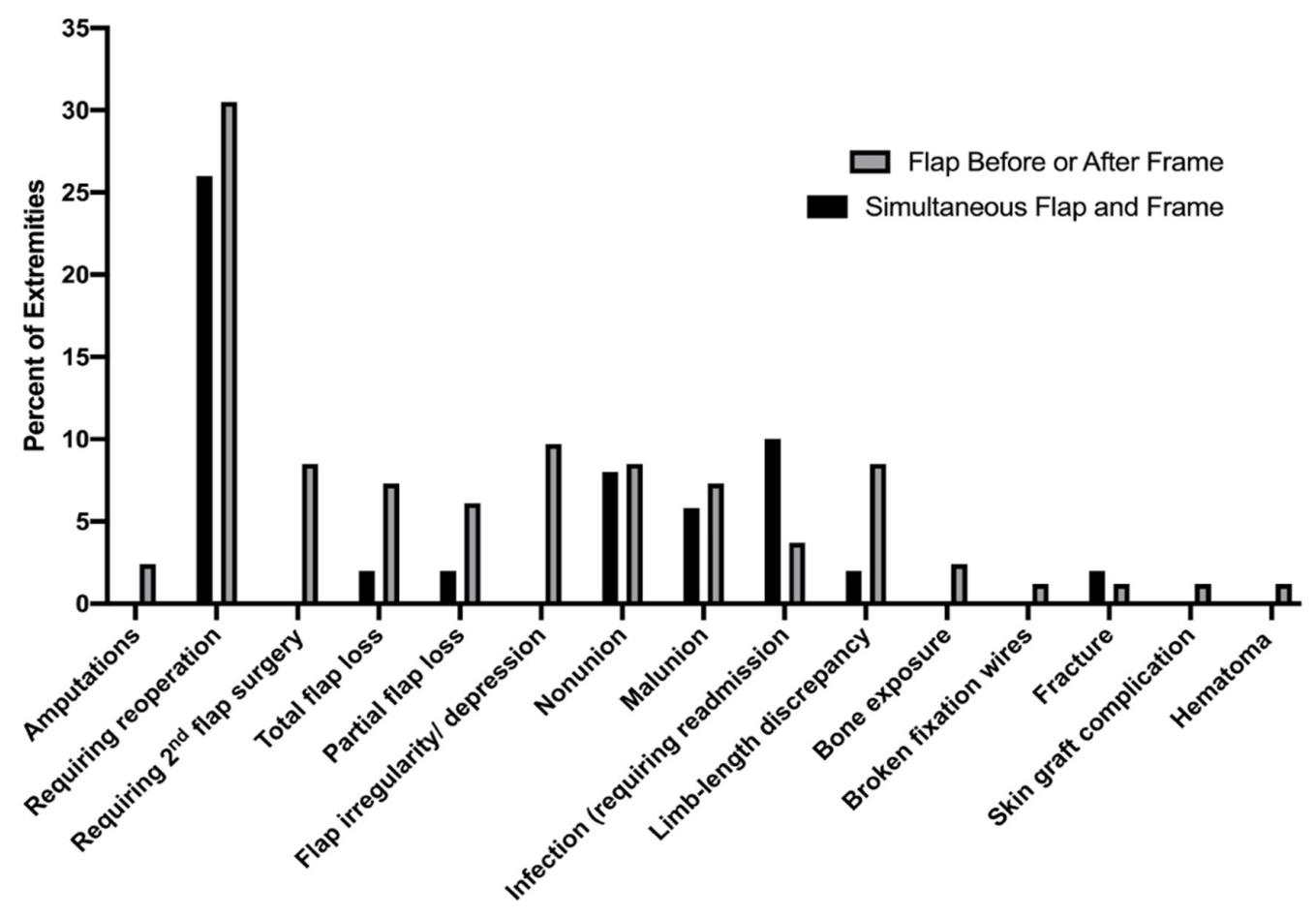

Complication

Figure 2. Percentage of patients with complications after extremity soft tissue reconstruction, broken down by timing of soft tissue flap vs. bone transport frame placement

one of which is a 52-year-old male with a compound comminuted fracture of the distal leg, a resultant 14- $\mathrm{cm}$ tibial bony defect, and a large soft tissue defect. He received a free rectus abdominis muscle flap, which failed secondary to venous thrombosis about 55 days after injury. He then had a second and successful free rectus abdominis flap. Months later, he underwent bone transport, resulting in full weight bearing capacity 18 months after injury. Hutson et al. ${ }^{[88]}$ denoted two flap failures out of 19 extremities undergoing reconstruction with flaps first. The methods utilized were two latissimus dorsi free flaps to recipient posterior tibial arteries anastomosed in either end-to-side or end-to-end fashion, both resulting in flap failure. The patients were reported to later undergo bone distraction, although further soft tissue rearrangement, if any, was not mentioned. Lastly, Chim et al. ${ }^{[89]}$ reported on 28 extremities undergoing flap reconstruction before or after fixation, three of which failed. One patient had successful bone transport and was managed with distraction lengthening of soft tissue, whereas the other two had concurrent failure of distraction and were managed with amputations. One amputation occurred in a 34-year-old patient with a Gustilo II infected bony nonunion after a motor vehicle collision and an associated wound size of $50 \mathrm{~cm}^{2}$, who had a failed gracilis free flap to recipient posterior tibial artery with end-to-side anastomosis and venous commitantes in end-to-end fashion. The other amputation was on a 57-year-old patient with a Gustilo IIIB acute bone loss defect due to a crush injury and an associated wound size of $700 \mathrm{~cm}^{2}$, which was managed with a latissimus dorsi free flap through end-to-side anastomosis of posterior tibial artery and end-to-end anastomosis to anterior tibial venous commitantes.

Four studies with a total of 32 patients described the management of acute injuries. Regarding union, there was one nonunion and three malunions, while no patients suffered a refracture. Regarding the flap, there were 5 losses (three total and two partial) and 9 flap irregularities. Sixteen patients required a secondary reoperation, and seven of them were for the flap specifically. One patient suffered from a deep infection. 
There were five studies that characterized their wounds as chronic. However, Lowenberg et al. ${ }^{[61]}$ (1996) reported the lone study to clarify their complications and describe them. Of their 23 patients, six suffered from a complication. Ones of note include two with nonunion, one with malunion, and one with partial loss of a flap, in deep infection. Additionally, there was an increased rate of second surgery $(P=0.049)$, as five patents needed a second surgery - one for a flap replacement specifically following initial failure.

Despite significant complications and reoperations, $98.8 \%$ (range of $92.9 \%$ to $100 \%$ ) of patients averaged from 6 articles were ultimately weight bearing, and the success rate was $98.4 \%$ (range of $92.8 \%$ to $100 \%$ ) averaged across 11 articles. One of the 14 articles reported a satisfaction rate of $100 \%$ from the 34 patients involved.

\section{Cases}

Case 1: free anterolateral thigh flap with taylor spatial frame first

A 69-year-old male with a history of obesity and hypertension was involved in a motor vehicle collision 40 years prior that resulted in an open tibia fracture that was treated with plate fixation at that time. He recovered from that surgery and did well without complication until 2 years prior to presentation when he was found to have purulent drainage around the plate, which was treated at an outside facility with serial debridement and skin grafting. He was ultimately referred to our center at Keck Hospital and was found to have chronic osteomyelitis of the tibia. After thorough debridement of bone and soft tissue, he was left with $17.5-\mathrm{cm}$ bony defect of the tibia and a wound that was approximately $100 \mathrm{~cm}^{2}$. The bony defect was temporized with antibiotic spacer and culture-directed intravenous antibiotics until cultures were negative, at which point the patient was placed in a hexapod frame. Five days thereafter, he received free flap coverage of his large wound with an anterolateral thigh (ALT) fasciocutaneous flap anastomosed in end-to-side fashion into the posterior tibial vessels. Bony transport was initiated once he had completed 6 weeks of i.v. antibiotics and he could be scheduled for surgery for corticotomy, which was 98 days after his initial external fixator placement. He was distracted at a rate of approximately 0.5-1 mm per day. After two subsequent surgical revisions of his multiplanar external fixator, he underwent removal of the external fixator 505 days after his initial ex-fix placement, and he underwent a Masquelet procedure to complete bony union. He did suffer equinovarus deformity of the foot, for which he received tendon lengthening and ankle-spanning external fixation, as well as arthrofibrosis of his knee, for which he underwent two lysis of adhesions and quadricepsplasty. Currently, he is weightbearing as tolerated and proceeding to follow with physical therapy. At his most recent follow-up four years after presentation, he had achieved bony union but developed an infection for which he is currently being treated with oral antibiotics and is scheduled to undergo surgical irrigation and debridement.

\section{Case 2: free latissimus dorsi and rotational gastrocnemius flap with delayed NuVasive precise frame}

A 45-year-old man sustained a left Gustilo-Anderson IIIB tibia/fibular shaft fractures with an associated distal fibular fracture, for which he underwent debridement and open reduction external fixation at an outside facility. He was transferred to our services when it was determined that he would need soft tissue coverage of his extremity. He was taken to the operating room for debridement of necrotic fibula stripped of periosteum and antibiotic spacer placement. His bony defect was approximately $8 \mathrm{~cm}$ and his soft tissue wounds were approximately $75 \mathrm{~cm}^{2}$. Five days after his initial debridement at our institution, the patient received both a free latissimus myocutaneous flap anastomosed in end-to-end fashion to the anterior tibial vessels as well as a rotational gastrocnemius myocutaneous flap for coverage of a more posterior wound. Split thickness skin grafting was employed to cover his remaining non-critical wounds. He proceeded with physical therapy and was ultimately weight bearing; however, it thereafter became apparent that he had nonunion of his tibia fracture, likely due to the extensive zone of injury. As such, 276 days after this initial treatment, he was taken to the operating room for placement of motorized magnetic transport nail (Nuvasive, Aliso Viejo, CA) for bone transport. He started distraction 11 days after placement of bone 


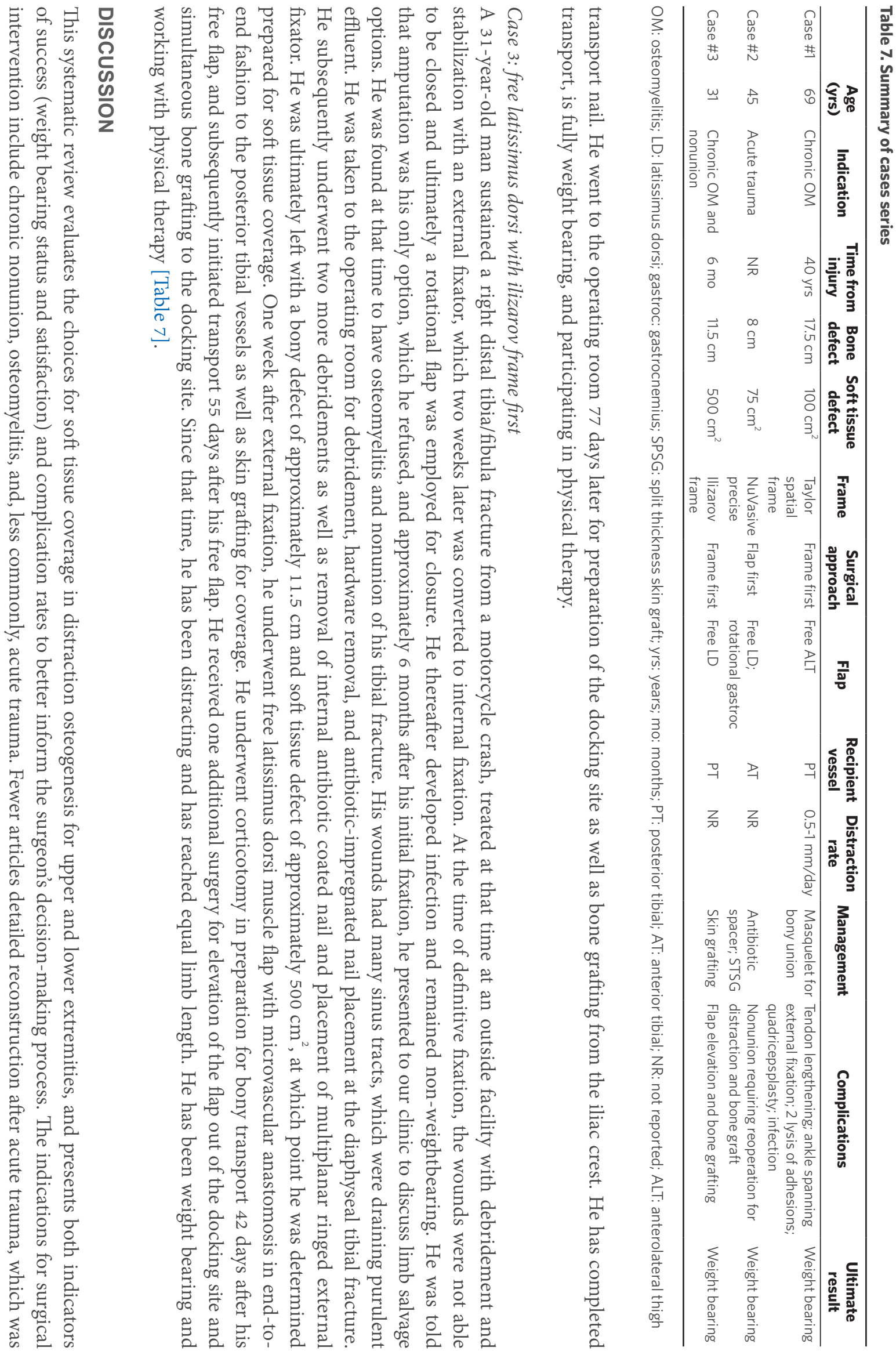


reflected in the longer than expected average time from injury (1.1 years), which ranged from within weeks to up to three years. Two cases in the present study describe treatment within days to a few weeks, whereas the other indicates over 40 years since initial injury, which better aligns with what is seen in our review of the literature. Additionally, the present study includes a single article that reports flap and frame repair of upper extremity injuries ${ }^{[6]}$. Although there is a paucity of literature discussing the use of soft tissue coverage and distraction osteogenesis in upper extremity reconstruction, the study was included to bring light to the innovative, diverse applications of this technique.

The current gold standard for managing large soft tissue defects that cannot be closed directly is the "fix and flap" protocol, which has several recognized advantages ${ }^{[4,51,59,60]}$. However, with respect to the results of our literature review, only about one third of the extremities described underwent simultaneous flap and frame placement. Similarly, this simultaneous approach is taken in only 1 of the 3 cases presented. While this is partially due to the inclusion of older studies that were published prior to the acceptance of modern "fix and flap" approach ${ }^{[7,9,41,61,62,65,84-86,88,89]}$, it is also important to note that the gold standard typically applies to acute traumatic injuries, whereas many patients undergoing bone transport are patients with chronic extremity issues.

With respect to reconstruction of bone, the present review measured the average bone defect to be $8.9 \mathrm{~cm}$, which required intervention to restore limb length. The mainstay of distraction osteogenesis is the application of the Ilizarov method for external fixation, although nowadays novel methods of complementary internal fixation have been innovated with improved patient comfort, decreased infection rates, and quicker recovery ${ }^{[43,91-95]}$. The present review identified that the majority of articles employed external fixation consistent with the Ilizarov method. The remaining articles used variations of the Ilizarov method, except one that used anterior double-stacking external fixation. However, for many reasons, an array of surgical techniques may be used to tailor reconstructive approach to the individual's unique presentation.

While bone defects smaller than $8 \mathrm{~cm}$ can be successfully closed using bone grafting ${ }^{[7,9,96]}$, larger defects may require a vascularized bone graft ${ }^{[97]}$. Common vascularized bone grafts that have been described include contralateral fibula and iliac crest ${ }^{[8]}$. These operations, however, carry significant donor site morbidity and are also limited by the size of the donor site ${ }^{[7,77]}$. For patients with large defects, the anatomy of the iliac crest makes it unsuitable ${ }^{[27]}$, and harvesting a contralateral fibula in a patient with unilateral lower extremity trauma can be problematic due donor site complications ${ }^{[98]}$ and insufficient pedicle length ${ }^{[99]}$. In certain circumstances, specifically in previously infected femoral shafts, efficacy has been shown for vascularized fibular grafts ${ }^{[100]}$. As seen in the present review, $62.3 \%$ of extremities were managed with both distraction osteogenesis and bone grafting. Two of the three cases discussed similarly received bone grafts.

When comparing bone grafting with soft tissue coverage against resection and bone transport, results have been shown to be similar, with significantly less limb length discrepancy in the bone transport group ${ }^{[101]}$. Although distraction osteogenesis in combination with free flap reconstruction has clearly been proven to be a useful treatment modality, the procedure is time consuming and can produce a multitude of challenging complications if not approached with great care.

Some of the common complications associated with this procedure are bone exposure ${ }^{[94]}$, nonunion ${ }^{[7]}$, flap necrosis ${ }^{[102]}$, and downward depression of the flap ${ }^{[90]}$. While some of the problems can be resolved with conservative care or minor revisions, there are others with more serious consequences. As found in the present review, flap failure may result from venous thrombosis or vasculature disruption due to acute or chronic pathologies ${ }^{[81,82,88,89]}$. The articles described these losses in patients with large bony and soft tissue defects undergoing a number of different free flaps (latissimus dorsi, rectus abdominis, and 
gracilis) through both end-to-end and end-to-side anastomoses to either anterior or posterior tibial vessels, consistent with the most frequently used surgical techniques. While two patients eventually underwent amputations, this adverse event was seen in only $1.4 \%$ of all extremities. Likewise, there was no statistically significant difference in rates of flap failure or amputation between the extremities that were managed according to the "fix and flap protocol" versus the placement of a flap before or after the frame. While the difference in outcomes between the most commonly used free flaps, the rectus abdominis and latissimus dorsi flaps, would be beneficial to evaluate, this was not possible given the nature of the studies. Nearly all of the case series that were included in our review reported multiple different types of flaps that were used in their patients, however the results were not separated according to flap type.

Looking further into patient complications, the present study indicates that injuries managed in the acute setting were significantly more likely to undergo secondary surgical repair, compared to those who were chronic. While this may be due to more controlled surgical management of chronic wounds predating the beginning of the study time, the variability in injuries, patient morbidities, surgeon expertise, and postoperative care limits the value of this finding.

An additional issue that can arise during the distraction process is the necessity to revise pin position or flap configuration. In cases of flap necrosis, however, distraction is often delayed or stopped altogether, necessitating additional procedures such as bone grafting ${ }^{[102]}$. Thus, meticulous planning of the flap in addition to careful postoperative care is crucial for successful reconstruction.

Deciding the reconstructive method for soft tissue coverage can be challenging, as the options to choose from are vast. In the articles reviewed, free flaps and muscle flaps were more commonly utilized than rotational flaps and fasciocutaneous flaps, respectively. As for specific flaps, rectus abdominis flaps were used for the greatest number of extremities, whereas free latissimus dorsi flaps were cited in the greatest number of distinct articles. Microsurgical technique varied, with end-to-end anastomosis being used almost as often as end-to-side anastomosis. Recipient vessels were most commonly the anterior and posterior tibial arteries, although a diverse set of choices exist. Given the comparable success rates with all of these different techniques, flap choice is often left to the discretion of the surgeon.

Aside from infection and fracture, the present review found that simultaneous placement of flap and frame, or the "fix and flap" protocol, had fewer reported adverse events overall [Figure 1]. These results align with the well-documented faster union times but differ from reported lower infection rates in the current literature ${ }^{[59,60]}$, given that our review actually found a higher rate of infection in the simultaneous placement of flap and frame. Two of the cases presented required additional surgeries, one for knee arthrofibrosis and foot deformity and the other for flap elevation, bone grafting, and docking.

Other factors must be taken into consideration when attempting to mitigate the risk of flap loss, with one of which being rate of bone transport. While Jupiter et al ${ }^{[62]}$ concluded that the free tissue and the native tissue undergo equal amounts of stretch and lengthening, Horas et al. ${ }^{[103]}$ noted a difference in speed between bone transport and soft-tissue movement, which could potentially jeopardize the vascular pedicle secondary. This risk increases with the amount of transport needed. Interestingly, all of the papers assessed in the review performed distraction at a rate between 0.75 and $1 \mathrm{~mm}$ per day, indicating that there is agreement that this range of rates produces optimal results.

Although limb salvage and reconstruction through soft tissue coverage and distraction osteogenesis comes with substantial risk of complications and reoperations, outcomes remain strong. Over $98 \%$ of patients were ultimately weight bearing, and article authors on average reported rates of success and patient satisfaction as greater than $98 \%$. All three of the case examples outlined in the present study are fully weight bearing as tolerated and working with physical therapy. 
There are several limitations to the present review. Due to the paucity of literature evaluating the outcomes after utilizing soft tissue coverage and bone transport after critical bone loss for limb salvage, this systematic review was limited to case reports and case series. Thus, the quality of studies included is a limitation. In addition, the studies included are very heterogeneous with the parameters discussed and outcomes evaluated, which led to an even smaller group of articles coinciding with any one parameter. Given the degree of inconsistency in the way results were reported in each article, many studies had to be excluded, leading to a lower power. Lastly, reoperation for cancellous bone grafting for nonunion was frequently performed across articles; however, it remained unclear in the literature if this was an expected complication that needs anticipated surgery vs. an actual complication. These events were included under the category of bone grafting.

In conclusion, the reconstruction of extremities with critical bone loss, whether due to acute trauma, nonunion, or chronic osteomyelitis, remains a significant challenge for surgeons. Our findings suggest that no one surgical approach is superior, and the treatment algorithm ultimately remains a decision to be made between the surgeon and the patient. In patients with bone defects too extensive for autologous bone grafting or in patients who are not candidates for this approach, a combination of bone transport with soft tissue reconstruction remains an excellent choice for satisfactory functional outcomes.

\section{DECLARATIONS}

\section{Authors' contributions}

Made substantial contributions to conception and design of the study and performed data analysis and interpretation: Stoneburner J, Azadgoli B, Carey J, Marecek G

Performed data acquisition, as well as provided administrative, technical, and material support: Stoneburner J, Azadgoli B, Howell A, Tucker D

\section{Availability of data and materials}

All data is shared through the included tables and figures.

\section{Financial support and sponsorship}

None.

\section{Conflicts of interest}

All authors declared that there are no conflicts of interest.

\section{Ethical approval and consent to participate}

Not applicable.

\section{Consent for publication}

Not applicable.

\section{Copyright}

(c) The Author(s) 2020.

\section{REFERENCES}

1. Hao J, Cuellar DO, Herbert B, Kim JW, Chadayammuri V, et al. Does the OTA open fracture classification predict the need for limb amputation? A retrospective observational cohort study on 512 patients. J Orthop Trauma 2016;30:194-98.

2. Tonnesen PA, Heerfordt J, Pers M. 150 open fractures of the tibial shaft--the relation between necrosis of the skin and delayed union. Acta Orthop Scand 1975;46:823-35.

3. Gustilo RB, Simpson L, Nixon R, Ruiz A, Indeck W. Analysis of 511 open fractures. Clin Orthop Relat Res 1969;66:148-54.

4. Yazar S, Lin CH, Lin YT, Ulusal AE, Wei FC. Outcome comparison between free muscle and free fasciocutaneous flaps for reconstruction 
of distal third and ankle traumatic open tibial fractures. Plast Reconstr Surg 2006;117:2468-75.

5. Fischer MD, Gustilo RB, Varecka TF. The timing of flap coverage, bone-grafting, and intramedullary nailing in patients who have a fracture of the tibial shaft with extensive soft-tissue injury. J Bone Joint Surg Am 1991;73:1316-22.

6. Rodriguez ED, Bluebond-Langner R, Copeland C, Grim TN, Singh NK, et al. Functional outcomes of posttraumatic lower limb salvage: a pilot study of anterolateral thigh perforator flaps versus muscle flaps. J Trauma 2009;66:1311-4.

7. Tukiainen E, Asko-Seljavaara S. Use of the Ilizarov technique after a free microvascular muscle flap transplantation in massive trauma of the lower leg. Clin Orthop Relat Res 1993:129-34.

8. Weiland AJ. Current concepts review: vascularized free bone transplants. J Bone Joint Surg Am 1981;63:166-9.

9. Spiro SA, Oppenheim W, Boss WK, Schneider AI, Hutter AM. Reconstruction of the lower extremity after grade III distal tibial injuries using combined microsurgical free tissue transfer and bone transport by distraction osteosynthesis. Ann Plast Surg 1993;30:97-104.

10. Watson TJ. Distraction osteogenesis. JAAOS 2006;14:S168-74.

11. Haines NM, Lack WD, Seymour RB, Bosse MJ. Defining the lower limit of a "critical bone defect" in open diaphyseal tibial fractures. J Orthop Trauma 2016;30:e158-63.

12. Nauth A, Schemitsch E, Norris B, Nollin Z, Watson JT. Critical-size bone defects: is there a consensus for diagnosis and treatment? J Orthop Trauma 2018;32:S7-11.

13. Schemitsch EH. Size matters: defining critical in bone defect size! J Orthop Trauma 2017;31:S20-22.

14. Masquelet AC, Fitoussi F, Begue T, Muller GP. Reconstruction of the long bones by the induced membrane and spongy autograft. Ann Chir Plast Esthet 2000;45:346-53. (in French)

15. Masquelet AC, Begue T. The concept of induced membrane for reconstruction of long bone defects. Orthop Clin North Am 2010;41:27-37.

16. Masquelet AC, Kishi T, Benko PE. Very long-term results of post-traumatic bone defect reconstruction by the induced membrane technique. Orthop Traumatol Surg Res 2019;105:159-66.

17. Khan SN, Cammisa FP Jr, Sandhu HS, Diwan AD, Girardi FP, et al. The biology of bone grafting. J Am Acad Orthop Surg 2005;13:77-86.

18. Christian EP, Bosse MJ, Robb G. Reconstruction of large diaphyseal defects, without free fibular transfer, in Grade-IIIB tibial fractures. J Bone Joint Surg Am 1989;71:994-1004.

19. Aho OM, Lehenkari P, Ristiniemi J, Lehtonen S, Risteli J, et al. The mechanism of action of induced membranes in bone repair. J Bone Joint Surg Am 2013;95:597-604.

20. Henrich D, Seebach C, Nau C, Basan S, Relja B, et al. Establishment and characterization of the Masquelet induced membrane technique in a rat femur critical-sized defect model. J Tissue Eng Regen Med 2016;10:E382-96.

21. Pelissier P, Masquelet AC, Bareille R, Pelissier SM, Amedee J. Induced membranes secrete growth factors including vascular and osteoinductive factors and could stimulate bone regeneration. J Orthop Res 2004;22:73-9.

22. Spiegelberg B, Parratt T, Dheerendra SK, Khan WS, Jennings R, et al. Ilizarov principles of deformity correction. Ann R Coll Surg Engl 2010;92:101-5.

23. Ilizarov GA. Clinical application of the tension-stress effect for limb lengthening. Clin Orthop Relat Res 1990;8-26.

24. Ilizarov GA. The tension-stress effect on the genesis and growth of tissues: Part II. The influence of the rate and frequency of distraction. Clin Orthop Relat Res 1989;263-85.

25. Vauhkonen M, Peltonen J, Karaharju E, Aalto K, Alitalo I. Collagen synthesis and mineralization in the early phase of distraction bone healing. Bone Miner 1990;10:171-81.

26. Han CS, Wood MB, Bishop AT, Cooney WP 3rd. Vascularized bone transfer. J Bone Joint Surg Am 1992;74:1441-9.

27. Ikeda K, Yokoyama M, Okada K, Tomita K, Yoshimura M. Long-term follow-up of the vascularized iliac bone graft. Microsurgery 1998;18:419-23.

28. Dumont CE, Exner UG. Reconstruction of large diaphyseal defects of the femur and the tibia with autologous bone. Eur J Trauma Emerg Surg 2009;35:17.

29. Innocenti M, Abed YY, Beltrami G, Delcroix L, Manfrini M, et al. Biological reconstruction after resection of bone tumors of the proximal tibia using allograft shell and intramedullary free vascularized fibular graft: long-term results. Microsurgery 2009;29:361-72.

30. Bernstein M, Fragomen AT, Sabharwal S, Barclay J, Rozbruch SR. Does integrated fixation provide benefit in the reconstruction of posttraumatic tibial bone defects? Clin Orthop Relat Res 2015;473:3143-53.

31. Krappinger D, Irenberger A, Zegg M, Huber B. Treatment of large posttraumatic tibial bone defects using the Ilizarov method: a subjective outcome assessment. Arch Orthop Trauma Surg 2013;133:789-95.

32. Paley D, Maar DC. Ilizarov bone transport treatment for tibial defects. J Orthop Trauma 2000;14:76-85.

33. Rozbruch SR, Kleinman D, Fragomen AT, Ilizarov S. Limb lengthening and then insertion of an intramedullary nail: a case-matched comparison. Clin Orthop Relat Res 2008;466:2923-32.

34. Bernstein M, Fragomen A, Rozbruch SR. Tibial bone transport over an intramedullary nail using cable and pulleys. JBJS Essent Surg Tech 2018;8:e9.

35. Paley D. Problems, obstacles, and complications of limb lengthening by the Ilizarov technique. Clin Orthop Relat Res 1990:81-104.

36. Rozbruch SR, Fragomen AT, Ilizarov S. Correction of tibial deformity with use of the Ilizarov-Taylor spatial frame.J Bone Joint Surg 2006;88:156-74.

37. Feldman DS, Shin SS, Madan S, Koval KJ. Correction of tibial malunion and nonunion with six-axis analysis deformity correction using the Taylor Spatial Frame. J Orthop Trauma 2003;17:549-54.

38. Eidelman M, Katzman A. Treatment of complex tibial fractures in children with the taylor spatial frame. Orthopedics $2008 ; 31$.

39. Eidelman M, Bialik V, Katzman A. Correction of deformities in children using the taylor spatial frame. J Pediatr Orthop B 2006;15:387-95.

40. Fadel M, Hosny G. The taylor spatial frame for deformity correction in the lower limbs. Int Orthop 2005;29:125-9.

41. Al-Sayyad J. Taylor spatial frame in the treatment of pediatric and adolescent tibial shaft fractures. J Pediatr Orthop 2006;26:164-70.

42. Bernstein R, Fragomen R, Rozbruch R. Tibial bone transport over an intramedullary nail using cable and pulleys. JBJS Essent Surg Tech 
2018;8:e9.

43. Watanabe K, Tsuchiya H, Sakurakichi K, Yamamoto N, Kabata T, et al. Tibial lengthening over an intramedullary nail. J Orthop Sci 2005; 10:480-5.

44. Xiong L, Gazyakan E, Kremer T, Hernekamp FJ, Harhaus L, et al. Free flaps for reconstruction of soft tissue defects in lower extremity: a meta-analysis on microsurgical outcome and safety. Microsurgery 2016;36:511-24.

45. Sofiadellis F, Liu DS, Webb A, Macgill K, Rozen WM, et al. Fasciocutaneous free flaps are more reliable than muscle free flaps in lower limb trauma reconstruction: experience in a single trauma center. J Reconstr Microsurg 2012;28:333-40.

46. Hong JP, Shin HW, Kim JJ, Wei FC, Chung YK. The use of anterolateral thigh perforator flaps in chronic osteomyelitis of the lower extremity. Plast Reconstr Surg 2005;115:142-7.

47. Cho EH, Shammas RL, Carney MJ, Weissler JM, Bauder AR, et al. Muscle versus fasciocutaneous free flaps in lower extremity traumatic reconstruction: a multicenter outcomes analysis. Plast Reconstr Surg 2018;141:191-9.

48. Hanasono MM, Skoracki RJ, Yu P. A prospective study of donor-site morbidity after anterolateral thigh fasciocutaneous and myocutaneous free flap harvest in 220 patients. Plast Reconstr Surg 2010;125:209-14.

49. Wei FC, Jain V, Celik N, Chen HC, Chuang DC, et al. Have we found an ideal soft-tissue flap? An experience with 672 anterolateral thigh flaps. Plast Reconstr Surg 2002;109:2219-26.

50. Bekara F, Herlin C, Somda S, de Runz A, Grolleau JL, et al. Free versus perforator-pedicled propeller flaps in lower extremity reconstruction: what is the safest coverage? A meta-analysis. Microsurgery 2018;38:109-19.

51. Samaha FJ, Oliva A, Buncke GM, Buncke HJ, Siko PP. A clinical study of end-to-end versus end-to-side techniques for microvascular anastomosis. Plast Reconstr Surg 1997;99:1109-11.

52. Khouri RK, Shaw WW. Reconstruction of the lower extremity with microvascular free flaps: a 10-year experience with 304 consecutive cases. J Trauma 1989;29:1086-94.

53. Kolker AR, Kasabian AK, Karp NS, Gottlieb JJ. Fate of free flap microanastomosis distal to the zone of injury in lower extremity trauma. Plast Reconstr Surg 1997;99:1068-73.

54. Stranix JT, Borab ZM, Rifkin WJ, Jacoby A, Lee ZH, et al. Proximal versus distal recipient vessels in lower extremity reconstruction: a retrospective series and systematic review. J Reconstr Microsurg 2018;34:334-40.

55. Byrd HS, Spicer TE, Cierney G 3rd. Management of open tibial fractures. Plast Reconstr Surg 1985;76:719-30.

56. Fischer JP, Wink JD, Nelson JA, Cleveland E, Grover R, et al. A retrospective review of outcomes and flap selection in free tissue transfers for complex lower extremity reconstruction. J Reconstr Microsurg 2013;29:407-16.

57. Pollak AN, McCarthy ML, Burgess AR. Short-term wound complications after application of flaps for coverage of traumatic soft-tissue defects about the tibia. The Lower Extremity Assessment Project (LEAP) Study Group. J Bone Joint Surg Am 2000;82:1681-91.

58. Colen DL, Colen LB, Levin LS, Kovach SJ. Godina's principles in the twenty-first century and the evolution of lower extremity trauma reconstruction. J Reconstr Microsurg 2018;34:563-71.

59. Hertel R, Lambert SM, Muller S, Ballmer FT, Ganz R. On the timing of soft-tissue reconstruction for open fractures of the lower leg. Arch Orthop Trauma Surg 1999;119:7-12.

60. Gopal S, Majumder S, Batchelor AG, Knight SL, De Boer P, et al. Fix and flap: the radical orthopaedic and plastic treatment of severe open fractures of the tibia. J Bone Joint Surg Br 2000;82:959-66.

61. Lowenberg DW, Feibel RJ, Louie KW, Eshima I. Combined muscle flap and Ilizarov reconstruction for bone and soft tissue defects. Clin Orthop Relat Res 1996:37-51.

62. Jupiter JB, Kour AK, Palumbo MD, Yaremchuk MJ. Limb reconstruction by free-tissue transfer combined with the Ilizarov method. Plast Reconstr Surg 1991;88:943-51.

63. Ilizarov GA, Zusmanovitch FN, Markhashov AM, Khelimskii AM, Levitina L, et al. Reconstruction of large defects of blood vessels on extremities by means of a gradual distraction. (An experimental study). Acta Chir Plast 1980;22:156-65.

64. Ilizarov GA, Kuznetsova AB, Peschanskii VS, Shchudlo MM, Khanes GS. Blood vessels in different systems of limb traction (experimental study). Arkh Anat Gistol Embriol 1984;86:49-55. (in Russian)

65. Fiebel RJ, Oliva A, Jackson RL, Louie K, Buncke HJ. Simultaneous free-tissue transfer and Ilizarov distraction osteosynthesis in lower extremity salvage: case report and review of the literature. J Trauma 1994;37:322-7.

66. Friedrich JB, Pederson WC, Bishop AT, Galaviz P, Chang J. New workhorse flaps in hand reconstruction. HAND 2012;7:45-54.

67. Larson N, Bishop T, Shin Y. Free medial femoral condyle bone grafting for scaphoid nonunions with humpback deformity and proximal pole avascular necrosis. Tech Hand Up Extrem Surg 2007;11:246-58.

68. Vedung T, Vinnars B. Ectopic bone formation after medial femoral condyle graft to scaphoid nonunion. J Wrist Surg 2014;3:46-9.

69. Penteado C, Masquelet A, Romana M, Chevrel J. Periosteal flaps: anatomical bases of sites of elevation. Surg Radiol Anat 1990;12:3-7.

70. Doi K, Hattori Y. Vascularized bone graft from the supracondylar region of the femur. Microsurgery 2009;29:379-84.

71. Sakai K, Doi K, Kawai S. Free vascularized thin corticoperiosteal graft. Plast Reconstr Surg 1991;87:290-8.

72. Muramatsu K, Doi K, Ihara K, Shigetomi M, Kawai S. Recalcitrant posttraumatic nonunion of the humerus: 23 patients reconstructed with vascularized bone graft: 23 patients reconstructed with vascularized bone graft. Acta Orthop Scand 2003;74:95-7.

73. Bakri K, Shin AY, Moran SL. The vascularized medial femoral corticoperiosteal flap for reconstruction of bony defects within the upper and lower extremities. Semin Plast Surg 2008;22:228-33.

74. Jadhav C, Rawlins J, Walters AG. Descending genicular vessels as recipient pedicle for free flap cover of complex defects around upper and mid-lower third junction of tibia. J Hand Microsurg 2015;7:326-7.

75. Jones DB Jr, Rhee PC, Shin AY. Vascularized Bone Grafts for Scaphoid Nonunions. J Hand Surg Am 2012;37:1090-4.

76. Kollitz KM, Pulos N, Bishop AT, Shin AY. Primary medial femoral condyle vascularized bone graft for scaphoid nonunions with carpal collapse and proximal pole avascular necrosis. J Hand Surg Eur Vol 2019;44:600-6.

77. Jones DB Jr, Bürger H, Bishop AT, Shin AY. Treatment of scaphoid waist nonunions with an avascular proximal pole and carpal collapse. 
a comparison of two vascularized bone grafts. J Bone Joint Surg Am 2008;90:2616-25.

78. Chang MA, Bishop AT, Moran SL, Shin AY. The outcomes and complications of 1,2-intercompartmental supraretinacular artery pedicled vascularized bone grafting of scaphoid nonunions. J Hand Surg Am 2006;31:387-96.

79. Doi K, Oda T, Soo-Heong T, Nanda V. Free vascularized bone graft for nonunion of the scaphoid. J Hand Surg Am 2000;25:507-19.

80. Jones B, Moran L, Bishop T, Shin Y. Free-vascularized medial femoral condyle bone transfer in the treatment of scaphoid nonunions. Plast Reconstr Surg 2010;125:1176-84.

81. Lowenberg DW, Buntic RF, Buncke GM, Parrett BM. Long-term results and costs of muscle flap coverage with Ilizarov bone transport in lower limb salvage. J Orthop Trauma 2013;27:576-81.

82. Musharafieh RS, Saghieh SS, Nassar H, Hamdan AM, Hashim HA, et al. Microvascular soft-tissue coverage and distraction osteosynthesis for lower-extremity salvage. Microsurgery 1996;17:666-73.

83. Bibbo C. Reverse sural flap with bifocal Ilizarov technique for tibial osteomyelitis with bone and soft tissue defects. J Foot Ankle Surg 2014;53:344-9.

84. Duman H, Sengezer M, Celikoz B, Turegun M, Isik S. Lower extremity salvage using a free flap associated with the Ilizarov method in patients with massive combat injuries. Ann Plast Surg 2001;46:108-12.

85. Minehara H, Yokoyama K, Sekiguchi M, Nakamura T, Shindo M, et al. Bone transport combined with free flap reconstruction and antibiotic bead spacers for a type IIIB open tibial fracture: case report. J Trauma 1998;44:1103-7.

86. Boopalan PR, Jepegnanam TS. Reverse sural flap cover within a ring fixator. Acta Orthop Belg 2010;76:684-8.

87. Lowenberg DW, Van der Reis W. One-stage muscle transfer and Ilizarov frame application. Tech Orthop 1996;11:144-9.

88. Hutson JJ Jr, Dayicioglu D, Oeltjen JC, Panthaki ZJ, Armstrong MB. The treatment of gustilo grade IIIB tibia fractures with application of antibiotic spacer, flap, and sequential distraction osteogenesis. Ann Plast Surg 2010;64:541-52.

89. Chim H, Sontich JK, Kaufman BR. Free tissue transfer with distraction osteogenesis is effective for limb salvage of the infected traumatized lower extremity. Plast Reconstr Surg 2011;127:2364-72.

90. Isik S, Guler MM, Selmanpakoglu N. Unexpected, late complication of combined free flap coverage and Ilizarov technique applied to legs. Ann Plast Surg 1997;39:437-8.

91. Napora JK, Weinberg DS, Eagle BA, Kaufman BR, Sontich JK. Hexapod frame stacked transport for tibial infected nonunions with bone loss: analysis of use of adjunctive stability. J Orthop Trauma 2017;31:393-9.

92. Napora JK, Weinberg DS, Eagle BA, Kaufman BR, Sontich JK. Hexapod stacked transport for tibial infected nonunions with bone loss: long-term functional outcomes. J Orthop Trauma 2018;32:e12-8.

93. Quinnan SM, Lawrie C. Optimizing bone defect reconstruction-balanced cable transport with circular external fixation. J Orthop Trauma 2017;31:e347-55.

94. Burghardt RD, Manzotti A, Bhave A, Paley D, Herzenberg JE. Tibial lengthening over intramedullary nails: a matched case comparison with Ilizarov tibial lengthening. Bone Joint Res 2016;5:1-10.

95. Paley D, Herzenberg JE, Paremain G, Bhave A. Femoral lengthening over an intramedullary nail. A matched-case comparison with Ilizarov femoral lengthening. J Bone Joint Surg Am 1997;79:1464-80.

96. Cierny G 3rd, Zorn KE, Nahai F. Bony reconstruction in the lower extremity. Clin Plast Surg 1992;19:905-16.

97. Yakuboff KP, Stern PJ, Neale HW. Technical successes and functional failures after free tissue transfer to the tibia. Microsurgery 1990;11:59-62.

98. Vail TP, Urbaniak JR. Donor-site morbidity with use of vascularized autogenous fibular grafts. J Bone Joint Surg Am 1996;78:204-11.

99. Mckee NH, Haw P, Vettese T. Anatomic study of the nutrient foramen in the shaft of the fibula. Clin Orthop Relat Res 1984;141-4.

100. Wei FC, El-Gammal TA, Lin CH, Ueng WN, Wei FC. Free fibula osteoseptocutaneous graft for reconstruction of segmental femoral shaft defects. J Trauma 1997;43:784-92.

101. Marsh JL, Prokuski L, Biermann JS. Chronic infected tibial nonunions with bone loss. Conventional techniques versus bone transport. Clin Orthop Relat Res 1994;139-46.

102. Kim J, Park Y. Reconstruction of the lower leg using the Ilizarov devices and latissimus dorsi free flap. J Korean Soc Plast Reconstr Surg 1996;23:1707-802.

103. Horas K, Schnettler R, Maier G, Schneider G, Horas U. The role of soft-tissue traction forces in bone segment transport for callus distraction. Strategies Trauma Limb Reconstr 2015;10:21-6. 